The same method, may be available as an adjunct to either Jamin's or Michelson's interferometers, except that here the transmitteddiffracted and reflected-diffracted rays are brought to interfere. To take the example of the Michelson type stripped of unnecessary details, let $g G g^{\prime}$ in the figure, be the grating or ruled surface, $n$ its normal, $L$ the source of white light, $M$ and $M$ the mirrors, and $E$ the eye. In the usual way the rays from $L$ interfere at $E$.

Now replace $L$ by a slit and collimator, $E$ by a telescope focussed for parallel rays. The eye at $E$ now sees a sharp line of light. At $D$ and $D^{\prime}$, however, there must be two diffraction spectra coinciding in all their parts and hence interfering rhythmically if all adjustments are sufficiently perfected. The other two diffractions within $M G g^{\prime}$ and $E G g$ are often lost at an incidence of $45^{\circ}$.

The attempt to produce these interferences $D, D^{\prime}$, with replica gratings is liable to result in failure: for while the transmitted system $N G D$ shows brilliant spectra, the reflected system $M G E$ is dull and hazy. Both spectra are clearly in evidence and may be brought to overlap. The film, however, does not reflect in a degree adequate to the transmission. Attempts are in progress to realize the condition of equality with a grating actually ruled on glass or possibly with a modified film.

What is strikingly feasible, however, with ordinary plate glass and a non-silvered grating, is the production of interferences between pairs of diffracted spectra, $D_{1}^{\prime}$ and $D_{1}$, for instance, if returned by equidistant mirrors $M_{1}$ and $N_{1}$ to a telescope in the line $D$. Both of these spectra are very brilliant and not very unequally so, and the coincidence of spectrum lines brings out the phenomenon. This is of the ring type, and not of the line type referred to above; but it also occupies the whole field of the spectrum from red to violet. In my first adjustment using sunlight, I obtained splendid large confocal ellipses, with the dark centers in the yellow, the sodium line simultaneously in focus serving as a major axis. It is more usual, however, to obtain oblique lines across the spectrum which are strongest in certain color fields. In a city laboratory these are perpetually in motion, the rings particularly alternating between dark and bright centers. Naturall a fine slit is of advantage. The theory of $\backslash$ hese ellipses will be given elsewhere.

\section{Cart Barus}

\section{NOTES ON AN EXPERIMENT CONCERNING THE NATURE OF UNIT CHARACTERS}

Some time ago the writer planned ${ }^{1}$ a series of experiments designed to throw some light on the nature of unit characters. Only one part, of which the following is a brief extract, has been completed. If an apology is necessary, for daring to present negative results, I might say that even if proof of a negative is logically impossible, such evidence does give an idea of the relative frequency of the occurrence of the event in question. It is sometimes forgotten that a small probable error is as desirable in this case as when the results are positive. In addition to this fact, however, it is a pleasure to call attention to a line of experimentation which, though familiar to all biologists, has not had the serious consideration that it deserves. I mean the work of MacDougal in trying to produce mutations or transmissible variations by artificial means. Even if one does not accept as fact that the definite and transmissible changes which have occurred in Dr. MacDougal's injection experiments were caused directly by the introduction of semi-toxic solutions into the mother plant's ovary, he should admit that the method proposed is well worth his earnest attention. It is capable of several modifications and extensions-two of which I shall describe-which if given sufficient trial might yield results with important bearings somewhat apart from the original scope of MacDougal's investigations. Even if many experiments on limited populations should give no positive results, it should be remembered that progressive variation occurs but rarely in nature, possibly but one variant in millions of individuals. One ought

${ }^{1}$ At the Connectiout Agricultural Experiment Station, under the federal appropriation known as the Adams fund. 
then to expect to increase this proportion only if he can multiply artificially the effectiveness of nature's causes; and it seems hardly reasonable to be disappointed if positive results are not obtained from experiments with only 1,200 or 1,500 plants.

One method which in spirit is an extension of the injection work was suggested by Osborne's investigations on plant proteids. Work on the ultimate composition of pure proteids has only been touched, but the fundamental researches that Osborne and his associates have carried on for the past twenty years have shown, even with the crude methods of our general analytic chemistry, that the proteids of different species of plants are very different in composition, the differences becoming more definite as the plants are further apart in the natural system. These facts immediately suggest the possibility that if the plant of one species could in its first life stages utilize the stored proteids of the endosperm or cotyledons of a very different type, changes would probably be induced in it, some of which might be heritable. This treatment is quite different from that where plants are fed different quantities of inorganic compounds in the form of the so-called essential elements of soil fertility. Food compounds and enzymes or producers of enzymes of a different kind from those ordinarily produced and used by the plant, are ready for its use in the very early formative period of ontogeny. If any changes can be expected to come about indirectly through changes in nutrition, they should be expected to occur under such treatment. It is possibly not a phenomenon that could occur naturally, yet since variations are caused by some cell activity different from the normal, they might very well be caused by the production of a different proteid or part of a proteid molecule, different from that normally produced but similar to what is produced by other plants. Then again similar conditions are probably produced when severe changes in temperature occur during the maturation of the seed. In fact, abnormal temperature conditions seem to have similar effects on somatic cells, for Webber $^{2}$ once stated that after the last great

${ }^{2}$ In a personal communication.
Florida "freeze" bud variations were very numerous in the trees that were severely injured. It is likely, too, that specialized parasites may have had changes in their own structure brought about in this way. Of course one must recognize the fact that a great many data are at hand on the effect of the stock upon an engrafted scion, all of which are negative or questionable. In this case, however, conditions are not similar. The bud or branch used as a scion is not at all in the same ontological stage as are the young seedlings in the experiments proposed. I have mentioned this matter at greater length than I had intended, but I have had the chance to try only some preliminary experiments with grafted cotyledons, and hope the plans might find favor with others who could work on a larger scale.

The second experiment which included observations on 1,200 plants is somewhat different. There seemed a possibility at least that if certain characters are due to the presence of an enzyme, this enzyme might actually be added to a plant which had not inherited either the enzyme itself or the ability to produce it, if the proper time of addition and the proper method could be found. This is pure speculation with no analogies, although it is likely that the mosaic disease of tobacco is an enzyme effect that can be communicated by infection. This disease, however, is not inherited through the seed, and may prove to be bacterial.

The subjects selected for experiment were two varieties of tomatoes, Sutton's Best of All, a variety with red flesh, and Golden Queen, a variety with yellow flesh. Hurst had already shown that all tomatoes possessed yellow flesh and that presence and absence of red flesh acts as a simple Mendelian pair. In order to be certain that we are dealing with the same characters, however, the two varieties were crossed and Hurst's work corroborated. Golden Queen, the yellow variety, was grown to flowering in sterilized soil. Flowers were castrated and bagged. When the stigmas were receptive they were pollinated with pollen from the same plants, which had been kept pure by bagging. At intervals of one hour after pol- 
linating - up to fifteen hours-different ovaries were injected with one of three solutions. Solution one was obtained by macerating one part by volume of seeds of the red variety in four parts water. Solution two was made by macerating the flesh of ripening fruit of the red variety and adding 50 per cent. water. Solution three was made by macerating pollen from the red variety in about nine times its bulk of water and filtering.

Seed was obtained from most of the injected ovaries, but the resulting fruits gave absolutely no trace of red coloration. The seeds from the treated ovaries were again planted in sterilized soil and gave nothing but normal Golden Queen fruit.

I have no doubt but that an experiment of this kind seems utter foolishness; most experiments yielding negative results do. Biologists, however, have generally accepted the suggestion of physiological chemists that life processes are in the nature of enzyme processes. Perhaps this is because one is behind a safe barrier of ignorance when he speaks of enzymes. But in the case of plant sap colors and animal pigments there certainly is reason to believe that their production is accelerated by enzyme action. If this is true, color-producing enzymes should show action comparable to that of other enzymes. As to the general properties of enzymes, however, little is known. Perhaps they can be stated in the following definition. Enzymes are catalysts that have thus far been produced only by living organisms. Two of their properties may be mentioned that especially interest us here: one, which they hold in common with inorganic catalysts, that of changing the rapidity of progress of a reaction already initiated, but not appearing in the final product; the other, that of possessing colloidal nature and a large molecule. The size of the molecules of all known enzymes and their colloidal nature makes it improbable that any extract containing a color-producing enzyme should reach the ovules of a treated ovary; it is not at all impossible, however, that such an extract might come in contact with the male nucleus as it is journeying from the stigma to the micropyle. Further, if one may argue from the work that has been done on artificial digestion, enzymes should be able to do their work after extraction. This work, then, simply shows. failure under the conditions described. It may be that failure should always be expected, yet with proper analysis of some of the attendant physical and chemical processes, some valuable results might be obtained.

\section{HARVARD UNIVERSTTY}

E. M. EAST

\section{TROUGH FAULTING IN THE SOUTHERN ADIRONDACKS ${ }^{1}$}

For some years certain prominent physiographic features in the eastern Adirondacks have been regarded as due chiefly to normal faulting. Thus, many of the conspicuous. mountain- ridges, lakes, and drainage lines strike north-northeast and south-southwest and are undoubtedly largely dependent upon. faults striking in the same direction. Within the pre-Cambrian crystalline rock area, it is: almost impossible to work out these faults in detail, but, along the border of the Adirondacks, where the Paleozoic sediments overlap upon the crystallines, the faults are often well shown, especially where they affect both the pre-Cambrian and Paleozoic masses. Attention is here directed to the well-known series of Mohawk valley faults which nearly all downthrow on the east side, often have branches, and sometimes extend northward into the pre-Cambrian area. The faults and minor cross faults of Clinton county, near Lake Champlain, are also well known. Thus far no rather extensive trough faulting has been definitely described in the Adirondack region, the comparatively small trough block between the Little Falls and Dolgeville faults. being perhaps the best illustration. It is the purpose of this article to call attention to a case of trough faulting on a large scale and also to point out the probable importance of this type of faulting in the Adirondacks.

Within the Broadalbin quadrangle (FultonSaratoga counties), which the writer is at present engaged in studying, detailed work

${ }^{1}$ Published by permission of the New York. state geologist. 